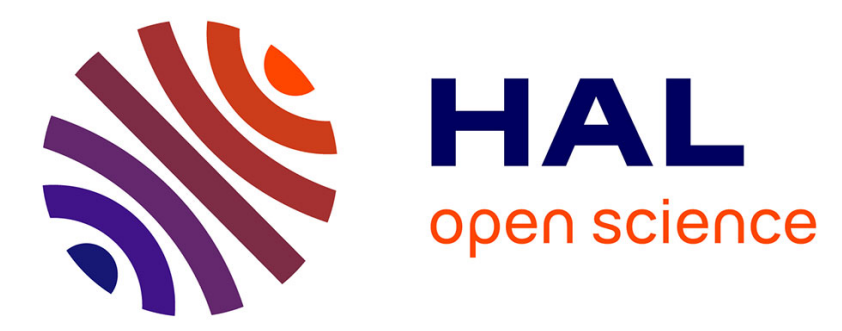

\title{
Visual Aesthetic Preference: Effects of Handedness, Sex, and Age-Related Reading/Writing Directional Scanning Experience.
}

Maria de Agostini, Seta Kazandjian, Céline Cavezian, Joseph Lellouch, Sylvie Chokron

\section{To cite this version:}

Maria de Agostini, Seta Kazandjian, Céline Cavezian, Joseph Lellouch, Sylvie Chokron. Visual Aesthetic Preference: Effects of Handedness, Sex, and Age-Related Reading/Writing Directional Scanning Experience.. Writing Systems Research, 2010, pp.1-9. doi: 10.1093/wsr/wsq006. 10.1093/wsr/wsq006 . inserm-00567844

\section{HAL Id: inserm-00567844 https://www.hal.inserm.fr/inserm-00567844}

Submitted on 11 Aug 2011

HAL is a multi-disciplinary open access archive for the deposit and dissemination of scientific research documents, whether they are published or not. The documents may come from teaching and research institutions in France or abroad, or from public or private research centers.
L'archive ouverte pluridisciplinaire HAL, est destinée au dépôt et à la diffusion de documents scientifiques de niveau recherche, publiés ou non, émanant des établissements d'enseignement et de recherche français ou étrangers, des laboratoires publics ou privés. 
De Agostini, M., Kazandjian, S., Cavézian, C., Lellouch, J. and Chokron, S. Visual Aesthetic Preference: Effects of Handedness, Sex and Age-related Reading/Writing Directional Scanning Experience. Writing Systems Research, 2010, 1-9. doi: 10.1093/wsr/wsq006

\title{
Visual Aesthetic Preference: Effects of Handedness, Sex, and Age-Related Reading/Writing Directional Scanning Experience
}

\author{
Maria DE AGOSTINI ${ }^{1,2}$, Seta KAZANDJIAN ${ }^{3,4,5}$,éline CAVEZIAN ${ }^{3,4,5}$, Joseph \\ LELLOUCH $^{1,2}$, and Sylvie CHOKRON ${ }^{3,4,5}$
}

1 : Inserm, CESP Centre for Research in Epidemiology and Population Health, U1018, Team 10, F-94807, Villejuif, France

2 : Univ Paris-Sud, UMRS 1018, F-94807, Villejuif, France

3 : Laboratoire de Psychologie et NeuroCognition, CNRS UMR 5105, Grenoble, France

4 : ERT Treat Vision, CNRS UMR 5105 and Service de Neurologie, Fondation Ophtalmologique

Rothschild, 75019 Paris, France

5 : Service de Neurologie, Fondation Ophtalmologique Rothschild, Paris, France

Corresponding author:

Maria DE AGOSTINI

Inserm, CESP U1018, Equipe 10

16 avenue P. Vaillant Couturier

F-94807 Villejuif

Email : maria.deagostini@inserm.fr 



\begin{abstract}
Most studies of visual aesthetic preference report that right-handers prefer pictorial arrangements possessing left-to-right directionality and/or containing the region of greatest weight or interest on the right side. However, visual aesthetic preference has also been linked to directional scanning depending on the individual's reading/writing habits. The present study aims to assess the respective role of biological factors, related to the functional specialization of the two cerebral hemispheres, indexed by handedness, and cultural factors (age-related reading/writing habits) in visual aesthetic preference. For this purpose, we tested the effects of handedness, sex and age on visual aesthetic preference in 40 children and 40 adults. Results revealed effects of handedness, sex, and age as well as a relationship between directional scanning, reading/writing habits and handedness. The question of a dynamic model of cerebral specialization based on interplay between cerebral plasticity and cultural/environmental factors is raised.

Key words: Aesthetic preference, development, vision, hemispheric specialization, handedness, sex, reading/writing habits.
\end{abstract}




\section{Introduction}

There is some evidence of a relationship between handedness and cognitive performance particularly between handedness and perceptual asymmetries (Annett, 2002) but the link between handedness and aesthetic preference remains a controversial. Most studies have reported that right-handers but not left-handers prefer pictorial arrangements possessing left-to-right directionality (for example, an image depicting a horse with a rightward gallop) and/or containing the region of greatest weight or interest on the right side (for example, a scene with a landscape with the most important objects on the right side; Beaumont, 1985; Freimuth and Wapner, 1979; Levy, 1976; Mead and McLaughlin, 1992). In left-handers, Levy (1976) found no evidence of systematic preference, whereas McLaughlin at al (1983) did find that this group tended to prefer asymmetric paintings whose area of interest was in the left half of the picture.

The two main explanations proposed to account for this right hemispatial visual preference in right-handers involve hemispheric activation. One proposition has been that when the focus of interest is lateralized to the right side of the image, the left hemisphere (LH) is activated, which corrects for the imbalance produced by the over-activation of the right hemisphere (RH) induced by pictorial viewing (Levy, 1976; Goldstein, 2001). In contrast, other authors have suggested that the rightward position of the focus of interest of an image would attract the viewer's gaze, leaving most of the picture in the left visual field and allowing the RH to analyze the pictorial information (Beaumont, 1985).

Recently it was demonstrated that far from being solely dependent on hemispheric specialization, visual aesthetic preference can be influenced by visuo-perceptual and/or motoric exploratory strategies. When left-to-right and right-to-left readers were presented opposite-facing picture pairs possessing directionality, the participants' preference was related to reading/writing 
directionality (Nachson, Argaman and Luria, 1999; Chokron and De Agostini, 2000). Nevertheless, it is interesting to note that if reading/writing habits seem to determine the preference for pictures expressing directionality, they do not modulate preference for landscape pictures with no directional information. For these non-directional pictures, a rightward preference was expressed by right-handed viewers irrespective of their reading habits, from leftto-right or from right-to-left (Chokron and De Agostini, 2000). These findings raise the question of an interaction between cultural factors (picture directionality related to reading/writing directionality) and cerebral dominance (rightward preference for pictures without manifest directionality regardless of the viewer's reading/writing habits) in aesthetic preference tasks.

However, using drawing tasks instead of perceptual ones, several authors have demonstrated that handedness and reading/writing habits may influence the preferred directionality (Reed and Smith, 1962; Gesell and Ames, 1947; Rice, 1930; Singh et al, 2000; Vaid et al, 2002). For example, Shanon (1979) compared right- and left-handers with different reading habits (left-to-right or right-to-left) using graphomotor and drawing tasks. He showed that directionality of right-handers with either reading habit seems determined by biological factors, whereas left-handers are more influenced by environmental factors and exhibit compromises when these are in conflict with the biological factors.

Although a motor component is undoubtedly implicated in directional drawings (Picard, 2010), it is very likely that a perceptuo-motor integration is reflected by the 'directionality' preference. Takala (1951) has thus noticed that the perceptual object itself appears to acquire the quality of 'directedness', with the feeling by some participants of being able to draw a picture only in a given direction, the opposite direction seeming 'wrong'. As Alter (1989) pointed out, directionality in drawing could be related to a perceptual ordering or directional scanning bias. 
In children, directionality expressed in visuo-motor tasks is generally related to handedness. Drawing a horizontal line is one of the tasks that particularly differentiate between right- and left-handed children: right-handers are predominantly right-directed whereas lefthanders predominantly show a left directionality for horizontal line drawing (Scheirs, 1990). In other visuo-motor tasks, such as drawing a profile of a human face, a predominant lateral direction is usually found in right-handed adults (profiles facing to the left) but not in left-handed adults (De Agostini and Chokron, 2002). The few studies that investigated the perceptual aspects of directionality or hemispatial predominance in children show that these lateral biases are related to handedness. A natural left-to-right trend (e.g., seen prior to reading education) in directionality exists only in right-handed children (Dreman, 1974).

The influence of another biological factor studied in this experiment is the sex effect. In the 1970s, a large debate on possible sex differences in functional brain lateralization was a central point in neuropsychological literature. A difference in language and visuospatial lateralization has been suggested with greater hemispheric specialization seen in males than in females, at least in right-handers (Kimura, 1999). Consistent with this hypothesis, Cela-Conde and colleagues (2009), using magnetoencephalography to record brain activity during an aesthetic preference task, found a bilateral activation in parietal regions in women, whereas it was lateralized in the right hemisphere in men. However, some reviews of literature data tend to minimize this sex difference, suggesting this could account only for $1 \%$ to $2 \%$ of the variance in laterality (Hiscock et al., 1995).

In the present paper we test for the effect of both age and handedness, in males and females, on visual aesthetic judgment. As mentioned earlier, using a visual aesthetic preference paradigm, we were recently able to demonstrate that healthy, right-handed children and adults 
significantly prefer pictures possessing the same directionality as their reading/writing habits (Chokron and De Agostini, 2000). Indeed, right-handers (children and adults) with left-to-right reading/writing habits significantly prefer pictures with a left-to-right directionality over their mirror representation. This left-to-right preference might be due both to their functional organization (as right-handers) and to their left-to-right scanning when reading.

As a matter of fact, biological directionality and reading/writing habits lead to the same directional bias in aesthetic preference only for right-handers, at least in readers of left to right languages. However, for left-handed individuals, the reported right-to left directional bias in left to right readers (Karev, 1999; De Agostini and Chokron, 2002) may change over time as a function of learning to read from left-to-right. Reading education has been found to shift directional preferences among children. Nachson et al. (1983) found that Israeli school children with a native right-to-left reading language demonstrated shifts in directional preference to leftto-right with increased exposure to written English. Furthermore, bi-literate children who learned English and Hebrew concurrently showed a different directional pattern compared with monoliterate English or Hebrew reading children. Thus, with greater exposure to reading a leftto-right language, the directional preference is likely to also strengthen. By testing both the effect of age and handedness on visual aesthetic preference as well as that of sex, we aim to investigate the interaction between biological and cultural factors in such processing. In this way, if the performance of left-handers changes with age, it may reflect the growing effect of reading/writing directionality on visual scanning. In the present experiment, we chose images of objects with directionality that are identified as static, moving or that possess no directionality (: e.g., landscapes) in order to assess the effect of these dimensions on visual aesthetic preference.

\section{METHOD}




\section{Participants}

Forty French children aged from 7 to 10 years $[\mathrm{m}=8.9(0.6)]$ and 40 French adults aged from 20 to 30 years $[\mathrm{m}=22.9,(2.9)]$, neurologically normal, participated in the study. In each age group there were 20 males and 20 females. Half of them were strongly right-handed and the remaining half were strongly left-handed. The children's hand preference was assessed using an instrument reported in De Agostini and Dellatolas (1988), and that of the adults by the questionnaire reported in Dellatolas et al. (1988). Children were tested in their school following informed consent from parents. Adult participants provided informed consent.

\section{Materials}

The Aesthetic Preference Task administered is composed of 50 stimuli. For each stimulus there are two mirror-image representations, positioned vertically on a sheet $(21 \times 29.6 \mathrm{~cm})$. Stimuli were classified into three series as illustrated in Figure 1. Series 1 contained 20 pictures representing static objects (e.g. an asymmetric lamp); series 2 contained 20 pictures representing moving objects (e.g., a goose); series 3 contained 10 pictures representing landscapes (e.g., a sun umbrella on a beach).

For series 1 and 2, objects were located in the center of the sheet and they expressed a left-to-right or right-to-left directionality. For series 3, the most salient aspect of the landscape was positioned on the left ("left-landscape") or right ("right-landscape") half of the sheet. The stimulus pairs were displayed in a random order. For each series, in half of the pairs the object with a left-to-right directionality (or right preponderance for landscapes) was on the top of the sheet; in the remaining half of the pairs it was on the bottom.

Figure 1: Examples of stimuli used in Aesthetic Preference Task. 
Left-to-right: examples of a static and a moving objects where the left-to-right direction is presented in the top figure and an example of a landscape image where in the bottom figure, the relevant detail for identification is on the right side ("right-landscape").

\section{Procedure}

Participants were presented with 50 mirror-image pairs of stimuli located one above the other and were asked to indicate which stimulus was more interesting to look at or more aesthetically pleasing. Equivalence was not allowed. Participants' responses were coded as rightward preference when the chosen item was an object that either faced to the viewer's right or had the area of interest on the right of the landscape. The scores in each task (pictures series) are expressed in percentage of rightward preference: they varied from 0 (all leftward preference) to 1 (all right preference). A score of 0.5 revealed equal rates of rightward and leftward preference.

\section{RESULTS}

A linear mixed model analysis was carried out, with age, sex and handedness as betweensubjects variables, and picture series as a within-subject variable. Results showed two highly significant main effects: series (static figures, $\mathrm{m}=0.61$; moving figures, $\mathrm{m}=0.61$; landscapes figures, $\mathrm{m}=0.43 ; \mathrm{F}(2,144)=26.80 ; \mathrm{p}<.0001$ ) and handedness (right-handers, $\mathrm{m}=0.63$, left-handers $\mathrm{m}=0.47 ; \mathrm{F}(1,144)=20.94 ; \mathrm{p}<.0001)$. The effects of sex (males, $\mathrm{m}=0.53 ;$ females, $\mathrm{m}=0.57 ; \mathrm{p}=.17$ ) and age (children, $\mathrm{m}=0.52$; adults, $\mathrm{m}=0.58 ; \mathrm{p}=0.09$ ) were not significant at the .05 level. Nevertheless, the interpretation of the differences of main means is not simple because of the presence of significant 2- and even 3-order interactions between the variables (series by age: $F(2,144)=2.90 ; p=.05$; sex by manual preference by series: $F(2,144)=3.08 ; p<.05)$, which shows that the data have a complicated structure and makes separate task analysis necessary. The means 
are quasi identical for static and moving figures but very different from landscapes figures. A mixed model analysis including only static figures and moving figures showed that not only the main series effect but also its interactions with the other factors were far from statistical significance. This strongly suggests that moving and static figures behave similarly. So, we combined moving and static figures scores to create a new score (directional figures), a percentage of the right preference of the 40 items (Table 1). 
Table 1: Mean scores (from 0 to 1) for right preference in Directional and Landscape images, according to group age, manual preference, and sex.

\begin{tabular}{|c|c|c|c|c|c|}
\hline & & \multicolumn{2}{|c|}{ Males } & \multicolumn{2}{|c|}{ Females } \\
\hline \multirow[t]{3}{*}{ CHILDREN } & & $\begin{array}{l}\text { Right-handed } \\
(\mathrm{n}=10)\end{array}$ & $\begin{array}{l}\text { Left-handed } \\
(\mathrm{n}=10)\end{array}$ & $\begin{array}{l}\text { Right-handed } \\
(\mathrm{n}=10)\end{array}$ & $\begin{array}{l}\text { Left-handed } \\
(\mathrm{n}=10)\end{array}$ \\
\hline & Directional & $\begin{array}{l}0.62(0.13) \\
p=.01\end{array}$ & $\begin{array}{l}0.48(0.16) \\
n s\end{array}$ & $\begin{array}{l}0.72(0.16) \\
p=.002\end{array}$ & $\begin{array}{l}0.44(0.16) \\
\text { ns }\end{array}$ \\
\hline & Landscape & $\begin{array}{l}0.55(0.26) \\
\mathrm{ns}\end{array}$ & $\begin{array}{l}0.20(0.13) \\
\mathrm{p}<.0001\end{array}$ & $\begin{array}{l}0.52(0.30) \\
\mathrm{ns}\end{array}$ & $\begin{array}{l}0.49(0.17) \\
\text { ns }\end{array}$ \\
\hline \multirow[t]{3}{*}{ ADULTS } & & $(n=10)$ & $(n=10)$ & $(n=10)$ & $(n=10)$ \\
\hline & Directional & $\begin{array}{l}0.64(0.16) \\
p=.02\end{array}$ & $\begin{array}{l}0.70(0.21) \\
\mathrm{p}<.02\end{array}$ & $\begin{array}{l}0.77(0.15) \\
p=.0003\end{array}$ & $\begin{array}{l}0.53(0.24) \\
\mathrm{ns}\end{array}$ \\
\hline & Landscape & $\begin{array}{l}0.36(0.24) \\
n s\end{array}$ & $\begin{array}{l}0.36(0.24) \\
n s\end{array}$ & $\begin{array}{l}0.60(0.33) \\
n s\end{array}$ & $\begin{array}{l}0.35(0.25) \\
\mathrm{ns}\end{array}$ \\
\hline
\end{tabular}

The $\mathrm{p}$ value indicates a significant difference from zero of the asymmetry scores (original score minus 0.5 ); the values in the parentheses refer to standard deviations.

Separate analyses of variance were conducted on the directional figures and the landscape stimuli, with age, sex, and handedness as between-subjects variables.

In the ANOVA analysis for the directional figures, a significant handedness effect, $\mathrm{F}(1,72)=15.09, \mathrm{p}=.0002$, was found (right-handers $=0.69$, left-handers $=0.54$ ) as was a significant age effect, $\mathrm{F}(1,72)=6.27, \mathrm{p}=.01$ (with the mean score for children being 0.56 and that for adults, 0.66). There was no effect of sex, $\mathrm{p}=.85$ (males $=0.61$; females $=0.62$ ). Moreover, the interaction of handedness by sex was significant, $\mathrm{F}(1,72)=7.44, \mathrm{p}=.003$. As such, the data for males and females were subjected to separate analyses of variance.

In males, there was a significant effect of age (children, $\mathrm{m}=0.55$; adults, $\mathrm{m}=0.67$; $\mathrm{F}(1,36)=5.28 ; \mathrm{p}<.03$ ) but no effect of handedness (right-handers, $\mathrm{m}=0.63$; left-handers, $\mathrm{m}=0.59$; $\mathrm{p}=.40$ ). It must be noted that the interaction handedness by age was very close to significance $(\mathrm{F}(1,36)=3.65 ; \mathrm{p}=.06)$. In right-handed males no effect of age was found (children, $\mathrm{m}=0.62$; adults, $\mathrm{m}=0.64 ; \mathrm{p}=.71$ ) whereas in left-handed males this effect was significant (children, $\mathrm{m}=0.48$; adults, $\mathrm{m}=0.70 ; \mathrm{t}(18)=-2.61 ; \mathrm{p}=.01)$. In females, the ANOVA analysis showed a strong 
effect of manual preference (right-handers, $\mathrm{m}=0.74 ;$ left-handers, $\mathrm{m}=0.49 ; \mathrm{F}(1,36)=20.55$; $\mathrm{p}<.0001$ ), no significant effect of age (children, $\mathrm{m}=0.58$; adults, $\mathrm{m}=0.65 ; \mathrm{p}=.21$ ) and no interaction at all, $\mathrm{p}=.73$ (Figure 2).

Figure 2 : Series with directional figures

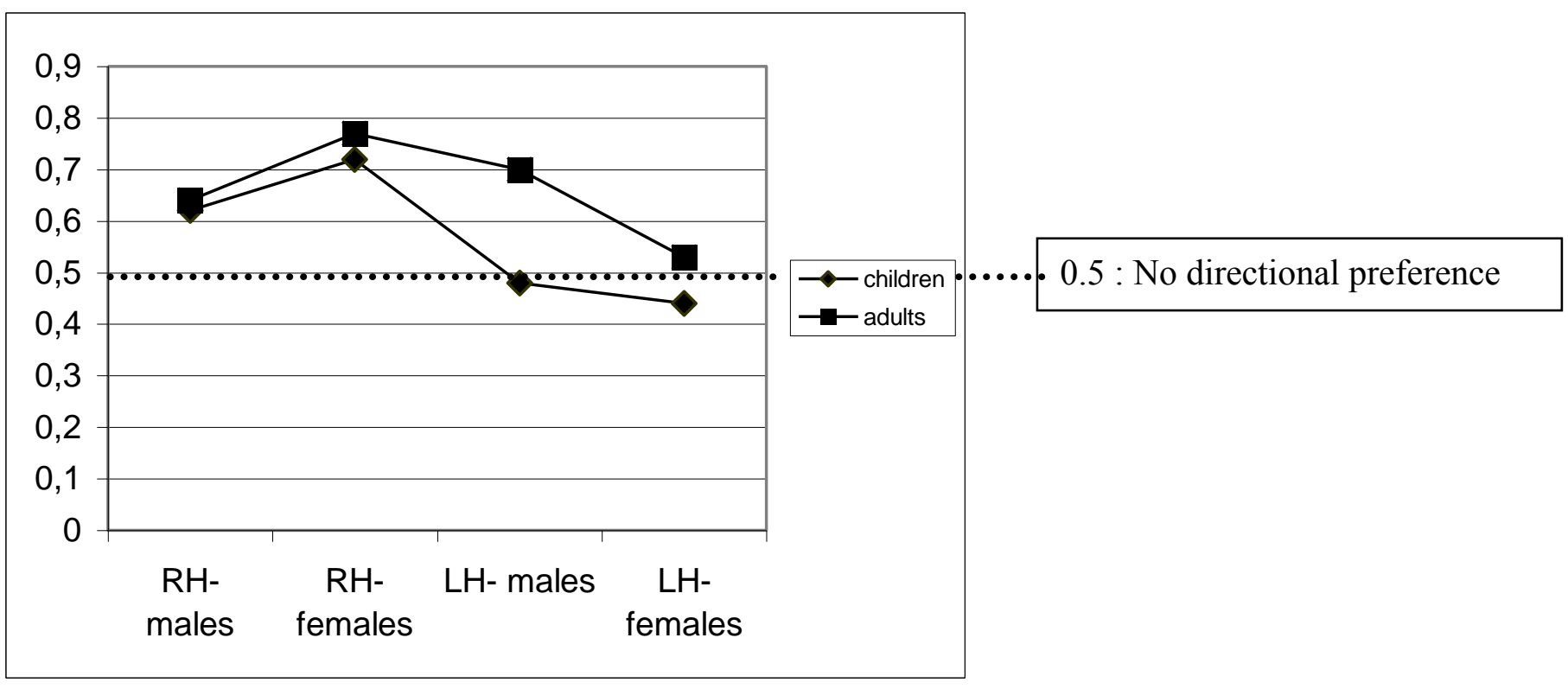

In summary, for the directional figures, the results are different in males and females. The handedness effect is strongly present in females (girls and women) with more right preference in right-handers and no age effect. In males, the handedness effect was present in children but not in adults; in fact the only participant group showing an age effect was the left-handed males group, whose right preference increased significantly with age.

In the ANOVA analysis for the landscape figures, significant handedness (right-handers, $\mathrm{m}=0.51$; left-handers, $\mathrm{m}=0.35 ; \mathrm{F}(1,72)=8.08 ; \mathrm{p}<.01$ ) and sex effects (males, $\mathrm{m}=0.36$; females, 
$\mathrm{m}=0.49 ; \mathrm{F}(1,72)=4.89 ; \mathrm{p}<.05$ ) were found, but not an age effect (children, $\mathrm{m}=0.44$; adults, $\mathrm{m}=0.42 ; \mathrm{p}=.69)$. The interaction handedness by sex by age was significant $(\mathrm{F}(1,72)=6.61 ; \mathrm{p}=.01)$ leading again to a separate analysis for males and females.

In males, a significant effect of handedness was found (right-handers, m=0.46; lefthanders, $\mathrm{m}=0.28 ; \mathrm{F}(1,36)=6.08 ; \mathrm{p}<.02$ ), but not an age effect (children, $\mathrm{m}=0.38$; adults, $\mathrm{m}=0.36$; $\mathrm{p}=.83)$. The interaction handedness by age was significant $(\mathrm{F}(1,36)=6.08 ; \mathrm{p}<.02)$. In fact, there was a nearly significant age effect in left-handers (children, $\mathrm{m}=0.20$; adults, $\mathrm{m}=0.36$; $\mathrm{t}(18)=-1.86$; $\mathrm{p}=.07$ ) and no effect in right-handers (children, $\mathrm{m}=0.55$; adults, $\mathrm{m}=0.36 ; \mathrm{p}=.11$ ). In females, the handedness effect (right-handers, $\mathrm{m}=0.56$; left-handers, $\mathrm{m}=0.42 ; \mathrm{p}=0.11$ ) and the age effect (children, $\mathrm{m}=0.51$; adults, $\mathrm{m}=0.48 ; \mathrm{p}=0.73$ ) were not significant and no interactions were found, $\mathrm{p}=.20$ (Figure 3).

Figure 3 : Series with landscape figures

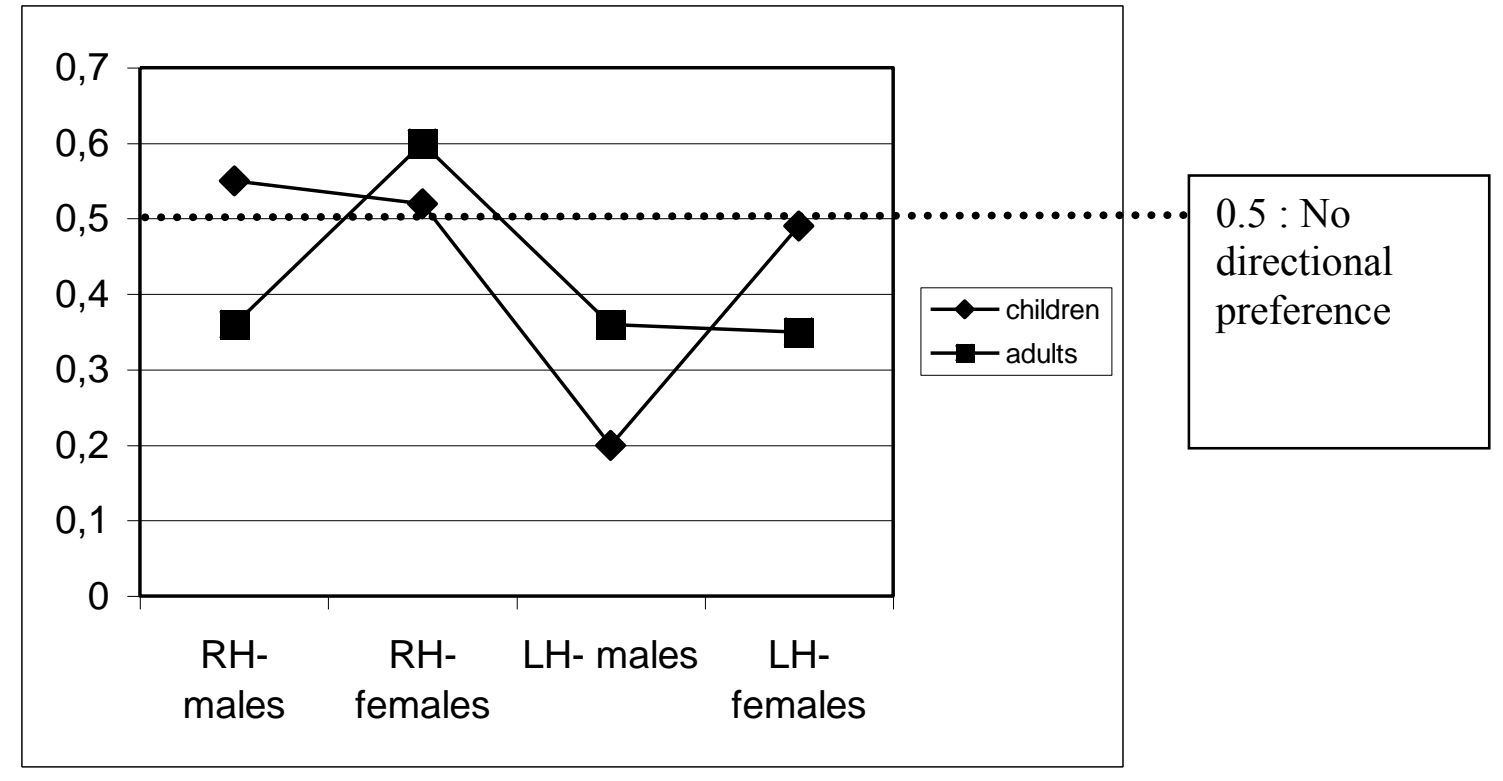


In summary, for the landscape figures, the results were different for males and females. In females, no handedness or age effect was found. In males, the interaction handedness by age shows that while no age effect was found in right-handers, a trend was present in the left-handed group whose right preference increased with age. The same interaction is present for variables directional and landscape figures in the left-handed male group. However, if right preference increases for both variables with age, for landscape figures, left preference is still predominant in adults.

\section{Discussion}

In the present paper we tested for the effects of both age and handedness in male and female participants on visual aesthetic judgments. The interaction between biological factors, such as cerebral lateralization (comparing right-/left-handers and males/females), and cultural factors, like reading/writing directional scanning experience (comparing children and adults) were explored. We also tested for the effect of stimuli characteristics using pictures with directionality (with static and moving objects) and without directionality (landscapes).

The present study confirms the effect of stimulus characteristics on the visual aesthetic preference task, found in a previous paper (Chokron and De Agostini, 2000). In this previous work, in right-handers with different directional reading/writing habits, we found a significant effect of reading/writing habits on aesthetic preference, with viewers preferring pictures with the same directionality as their reading/writing habits. In contrast, we found no significant effect of reading/writing habits for landscape images. In the present paper, the results for directional images of static and moving objects-were very similar, showing that preference was determined more by the directionality than by the static or mobile characteristics of the pictures. However the visual preference manifested for the landscape images was again different from the preference for 
directional pictures. In this way, the present results confirm earlier results and emphasize the fact that directional pictures and landscapes may be differentially processed.

Our results highlight the effect of the biological factors of handedness and sex on visual aesthetic judgment and a cultural effect (age-related reading/writing direction) at least in the lefthanded male group. Indeed, according to our hypothesis, based on the fact that biologicallybased directional preferences and reading/writing habits have the same directionality, in pictures with directionality all right-handed groups, children and adults, males and females, show a preference for stimuli depicting objects with a rightward directionality, i.e., in the same direction as the one used when reading. The age effect, which could also reflect the reading/writing directional scanning experience effect, was expected in left-handers, who present opposite biological/writing directionalities at an early stage of reading/writing. This significant change in visual preference for directional pictures was observed at least in left handed males who, from childhood to adulthood, significantly switch their preference for pictures with leftward directionality to pictures with a left-right directionality (according to their reading direction). We cannot exclude that this change stems from a natural maturational brain process in left-handers (Geschwind and Galaburda, 1985), but our results suggest that it could be seen as resulting from learning to read and write with a left-to-right direction.

In left-handers, if an atypical language cerebral representation has often been described (Szaflarski et al., 2002), the influence of familial sinistrality (not assessed in the current study) seems more important than the sex influence per se (Hécaen et al., 1981, and Bryden et al., 1983). Nevertheless, the interaction observed in the present study between sex and manual preference for directional images suggests that the environmental influence of reading/writing habits significanlty affects only the male participants' judgements. Left-handed adult female participants do no show any directional preference, as left-handed girls do. These results 
emphasize again the contribution of biological factors in visuospatial organization: females, at least left-handed females, would be less sensitive to the environmental influence than males.

It is by now well established that right- and left-handers, at least as groups, differ in cerebral lateralization of functions (Annett, 2002). Recently some studies have suggested that handedness should be considered on a continuum, based on method of measure, rather than as a dichotomy between right-handed and left-handed individuals (Bourne, 2008). In this study, given the greater variability in lateralization in left- versus right- handers, only strong right- or lefthanded individuals were tested. It is possible that our left-handed population has distinctive lateralization characteristics based on this methodological choice.

Differences in lateralization according to sex have also been found suggesting a greater hemispheric specialization in male compared to female right-handed adults (Kimura, 1999). More recently some studies have considered the interaction between handedness and sex. Bourne (2008), with a chimeric faces test, found a relationship between handedness and lateralization for men only. Along the same lines, in the present study the expected effect of directional acquired habits and handedness on lateralization was found only in men.

In summary, the current findings confirm previous studies among French and Israeli readers and raise the question of an interaction between cultural factors and cerebral dominance in visuospatial organization. The results demonstrate that despite biological factors associated with hemispheric specialization and the early presence of functional asymmetries (e.g., handedness) both of which influence scanning direction, environmental or cultural factors appear to contribute to the aesthetic preference of images. In this report we also highlight that the contribution of culture on aesthetic preference does not manifest to the same extent for lefthanded children and adults. In addition to age, a fourth factor - sex - intervenes in aesthetic preference judgments. Left-handed females appeared to be less influenced by their reading 
direction compared to left-handed males. In conclusion, culture, in the form of reading/writing directional scanning, does play an important role in the way one scans and represents visuospatial information. The extent of this influence and its possible effect on hemispheric specialization remains to be investigated.

Indeed, these results stress the need of complementary studies, especially in participants differing in manual preference and reading/writing habits, to disentangle biological and cultural factors more thoroughly. As discussed in previous papers (Chokron, 2002; Chokron, Kazandjian and De Agostini, in press; Kazandjian and Chokron, 2008), experimental studies dealing either with cognitive/perceptual biases and/or with hemispheric specialization only scarcely take into consideration the interaction between age, sex, manual preference and cultural influence (such as reading and writing direction). However, as the present findings underscore, we may need to study these factors concurrently in order to understand how nature and nurture interact in the perception and representation of the external world. 


\section{References}

Alter, I. (1989). A cerebral origin for "directionality". Neuropsychologia, 27, 563-573.

Annett, M. (2002). Handedness and Brain Asymmetry. New York: Taylor \& Francis.

Beaumont, J.G. (1985). Lateral organization and aesthetic preference: The importance of peripheral visual asymmetries. Neuropsychologia, 23, 103-113.

Bourne, V.J. (2008). Examining the relationship between degree of handedness and degree of cerebral lateralization for processing facial emotion. Neuropsychology, 22, 350-356.

Bryden, M. P., Hécaen, H., and De Agostini, M. (1983). Patterns of cerebral organization. Brain and Language, 20, 249-262.

Cela-Conde, C.J. (2009). Sex-related similarities and differences in neural correlates of beauty. Proceedings of the National Academy of Sciences, 106, 3847-3852.

Chokron, S. (2002). On the origin of free-viewing perceptual asymmetries, Cortex, 38, 109112.

Chokron, S. and De Agostini, M. (2000). Reading habits influence aesthetic preference.

Cognitive Brain Research, 10, 45-49.

Chokron S, Kazandjian, S., and De Agostini M. (2010, in press). Cultural and biological interaction in visuospatial organization. In A. Maass and T. Schubert (eds), Spatial dimensions of social thought. Mouton de Gruyter.

De Agostini, M., and Chokron, S. (2002). The influence of handedness on profile and line drawing directionality in children, young, and older normal adults. Brain and Cognition, 48, 333336.

De Agostini, M., and Dellatolas, G. (1988). Une épreuve simple pour évaluer la préférence manuelle chez l'enfant à partir de 3 ans. Enfance, 41, 139-147.

Dellatolas, G., De Agostini, M., Jallon, P., Poncet, M., Rey, M., and Lellouch, J. (1988). Mesure de la préférence manuelle par auto-questionnaire dans la population française adulte. Revue de Psychologie Appliquée, 38, 117-136.

Dreman, S. (1974). Directionality trends as a function of handedness and of reading and writing habits, American Journal of Psychology, 87, 247-253.

Freimuth, M. and Wapner, S. (1979). The influence of lateral organization on the evaluation of paintings, British Journal of Psychology, 70, 211-218. 
Geschwind, N. and Galaburda, A. M. (1985). Cerebral lateralization. Biological mechanisms, associations and pathology: I. A hypothesis and a program for research. Archives of Neurology, 42, 428-459.

Gesell, A. and Ames, L.B. (1947). The development of handedness. The Journal of Genetic Psychology, 70, 155-175.

Goldstein, E.B. (2001), Perception. Oxford: Blackwell Publishers, Ltd.

Hécaen, H., De Agostini, M., and Monzon-Montes, A. (1981). Cerebral organization in lefthanders, Brain and Language, 12, 261-284.

Heller, W. and Levy, J. (1981). Perception and expression of emotion in right-handers and lefthanders. Neuropsychologia, 19, 263-272.

Hiscock, M., Israelian, M., Inch, R., Jacek, C., and Hiscock-Kalil, C. (1995). Is there a sex difference in human laterality? II. An exhaustive survey of visual laterality studies from six neuropsychology journals. Journal of Clinical and Experimental Neuropsychology, 17, 590-610.

Karev, G. B. (1999). Directionality in right, mixed and left handers. Cortex, 35, 423-431.

Kazandjian, S. and Chokron, S. (2008). Paying attention to reading direction, Nature Reviews Neuroscience, 9, 965.

Kimura, D. (1999). Sex and Cognition. Cambridge, MA: MIT Press.

Levy, J. (1976). Lateral dominance and aesthetic preference. Neuropsychologia, 14, 431-445.

McLaughlin J.P., Dean P., and Stanley, P. (1983). Aesthetic preference in dextrals and sinistrals. Neuropsychologia, 21, 147-153.

Mead, A.M. and McLaughlin, J.P. (1992). The roles of handedness and stimuli asymmetry in aesthetic preference. Brain and Cognition, 20, 300-307.

Nachson, I. (1983). Directional preference of bilingual children. Perceptual and Motor Skills, 56, 747-750.

Nachson, I., Argaman, E., and Luria, A. (1999). Effects of directional habits and handedness on aesthetic preference for left and right profiles. Journal of Cross-Cultural Psychology, 30, 106114.

Picard, D. (2010, in press). Impact of manual preference on directionality in children's drawings. Laterality.

Reed, G.F. and Smith, A.C. (1962). A further experimental investigation of the relative speeds of left and right-handed writers. Journal of Genetic Psychology, 100, 275-87. 
Rice, C. (1930). Excellence of production and types of movements in drawing. Child Development, 1, 1-14.

Scheirs, J. G. M. (1990). Relationships between direction of movements and handedness in children. Neuropsychologia, 28, 743-748.

Shanon, B. (1979). Graphological patterns as a function of handedness and culture. Neuropsychologia, 17, 457-465.

Singh, M., Vaid, J., and Sakhuja, T. (2000). Reading/writing vs. handedness influences on line length estimation. Brain and Cognition, 43, 398-402.

Szaflarski, J.P., Binder, J.R., Possing, E.T., McKiernan, K.A., Ward, B.D., and Hammeke, T.A. (2002). Language lateralization in left-handed and ambidextrous people: fMRI data, Neurology, $59,238-244$.

Takala, M. (1951). Asymmetries of the Visual Space. Helsinki: Suomalaisen Kirjallisuuden Seuran Kirjapainon Oy.

Vaid, J., Singh, M., Sakhuja, T., and Gupta, G.C. (2002). Stroke direction asymmetry in figure drawing: Influence of handedness and reading/writing habits. Brain and Cognition, 48, $597-602$. 